\title{
The Nexus Between the Elasticity of Intertemporal Substitution and the Coefficient of Relative Risk Aversion
}

\author{
Samih Antoine Azar ${ }^{1}$ \\ ${ }^{1}$ Faculty of Business Administration \& Economics, Mexique Street, Kantari, Beirut, Lebanon \\ Correspondence: Samih Antoine Azar, Full Professor Faculty of Business Administration \& Economics, Mexique \\ Street, Kantari, Beirut, Lebanon. Tel: 96-1134-9230.
}

Received: June 5, 2018

Accepted: June 19, 2018

Online Published: June 24, 2018

doi:10.5430/ijfr.v9n3p98

URL: https://doi.org/10.5430/ijfr.v9n3p98

\begin{abstract}
One advantage of the Epstein-Zin preference function is that it disentangles the elasticity of intertemporal substitution (EIS) from the coefficient of relative risk aversion (CRRA). The paper subjects this preference function to statistical analysis. The methodology is to calculate the unconditional average of this new Euler equation and to find out if such an average is statistically insignificantly different from zero. Seventeen individual and different stocks are used. The results show that, when the EIS is fixed, the CRRA has multiple solutions. In some cases there are three solutions and not only two. Moreover these solutions extend to wide ranges.
\end{abstract}

Keywords: elasticity of intertemporal substitution, coefficient of relative risk aversion, recursive utility function, Epstein-Zin-Weil CCAPM Euler equation, unconditional mean, 17 US stock prices, multiple solutions

\section{Introduction}

The elasticity of intertemporal substitution (EIS) has a privileged place in macroeconomics and in finance. It measures the extent to which a rise in (expected) real interest rates affects the (expected) real growth in consumption. If the relation is positive then it measures the income effect. If it is negative then it measures the substitution effect. A large value for the EIS denotes a high propensity to substitute future consumption for today's consumption, and a low propensity to smooth out consumption, and hence less dislike for a growth in consumption. Originally the EIS and the coefficient of relative risk aversion (CRRA) were assumed to be inversely related, and consequently they were constrained to be such. However, the literature showed that the required CRRA ought to be very large to explain the magnitude of the equity premium (Mehra and Prescott, 1985). With an inverse relation, the EIS would have to be very small. The papers by Hall $(1978,1988)$ are classics, and it was not surprising for his time that Hall argued strongly for a small EIS, and he indeed finds evidence that the EIS may not be even significantly different from zero. This result, for a small EIS, has remained robustly anchored in the literature till quite recently (Thimme, 2017). The equity premium puzzle was instrumental in spurring a search for alternative utility functions which do not suffer from the above stated inverse relation between the EIS and the CRRA, and that may resolve the puzzle of a very high needed CRRA. This has led to what has been called constant elasticity-of-substitution (CES) aggregator functions, or "generalized", or even "recursive" non-expected utility functions. This paper builds upon this kind of utility functions. First, the EIS is mathematically defined as follows:

$$
E I S=-\partial \log \left(\frac{C_{t+1}}{C_{t}}\right) / \partial \log \left(\frac{\partial U / \partial C_{t+1}}{\partial U / \partial C_{t}}\right)
$$

Where $C$ is consumption and $U$ is a utility function with two arguments: $C_{t}$ and $C_{t+1}$.

The CES felicity function that is considered here has been developed by Epstein and Zin $(1987,2013)$ and Weil $(1989,1990)$ based upon the work of Kreps and Porteus $(1978,1979)$ on non-expected utility functions. It has the additional advantage that it is consistent with both the consumption CAPM and with the static CAPM. The empirical analysis was started by Epstein and Zin (1991), who used a broad stock market index, and later the empirics were extended by Stock and Wright (2000), Weber (2000), Samson and Armstrong (2007), and Kim and Ryou (2012). Most, if not all, authors have selected the Generalized Method of Moments (GMM) as the econometric procedure. GMM was formulated initially by Hansen and Singleton (1982) but suffers from the statistical artifact that it is very sensitive to the number and to the lags of the instruments. While the theoretical methodology is closely related to this 
literature, the statistical methodology in this paper uses the procedure introduced by Kocherlakota (1996), who tests, for statistical significance, the unconditional mean of the Euler equation of what has been called the Consumption CAPM model (CCAPM), originally formulated by Rubinstein (1976), Lucas (1978) and Breeden (1979). If statistical significance is found, then the CCAPM is rejected, and does not hold. Otherwise it does hold.

The mathematical model is as follows:

$$
\begin{gathered}
U\left(C_{t}, C E_{t+1}\right)=\left[(1-\beta) C_{t}^{1-\rho}+\beta C E_{t} \widetilde{U}_{t+1}^{1-\rho}\right]^{\frac{1}{1-\rho}} \\
C E_{t}\left(\widetilde{U}_{t+1}\right)=\left[E_{t} \widetilde{U}_{t+1}^{1-\gamma}\right]^{1 /(1-\gamma)} \\
E_{t}\left\{\left[\beta\left(\frac{C_{t+1}}{C_{t}}\right)^{-\rho}\right]^{\theta}\left[\tilde{R}_{t+1}^{m}\right]^{1-\theta} \tilde{R}_{t+1}^{j}\right\} \equiv 1
\end{gathered}
$$

$\theta=\left[\frac{(1-\gamma)}{(1-\rho)}\right], 0<\beta<1,1 \neq \gamma>0,1 \neq \rho>0$

$\frac{1}{\rho}:$ elasticity of intertemporal substitution

$\gamma$ : coefficient of relative risk aversion

$\beta$ : discount factor.

$E_{t}$ : expectation operator

$C_{t}$ : per capita real consumption

$U_{t}($.$) : felicity function$

$\tilde{R}_{t+1}^{m}$ : random return on wealth or on the "market"

$\tilde{R}_{t+1}^{j}$ : random return on a given asset, which can be the wealth random return

$t$ : time period

\section{Statistical Methodology}

The approach substitutes the gross log return of the S\&P 500 stock market index for $\tilde{R}_{t+1}^{m}$. While for $\tilde{R}_{t+1}^{j}$ seventeen different stocks that belong to the Dow Jones Industrial Average are selected. These are: $3 \mathrm{M}$, Boeing, Caterpillar, Chevron, Coca Cola, Disney, GE, IBM, Johnson \& Johnson, Merck, Mobil, Pepsi, Pfizer, Procter and Gamble, United Tech, and Walmart. In most finance textbooks a portfolio of 15 stocks is deemed large enough to eliminate idiosyncratic risk. The data is monthly and spans different periods. The shorter period has 542 observations and the longest has 667 observations, dating back to the early 1970s. The approach relies on generating a data table with two different parameters: $\rho$ and $\theta$. See Benninga (2005) for a review of the calculations in EXCEL of a data table. One such table is specific to each stock. The procedure is carried out by replacing conditional expectations with unconditional expectations. The average of equation (1) is measured, together with its standard error. The t-statistics are obtained by dividing the two. If the t-statistic is insignificant (a t-statistic $<1.96$ ) an indicator is defined that takes the value 1 , and 0 otherwise. Then the indicator variables are summed across the 17 stocks, and Table 2 is the result. A value of 4 in a cell, for example, means that four stocks out of 17 have an insignificant unconditional average in this cell. The corresponding EIS and CRRA can be easily retrieved from the cell frames. Kocherlakota (1996) chooses the first insignificant t-value of the unconditional average to pinpoint the required CRRA. If a higher CRRA leads to an insignificant t-value it is not considered to be part of the solution. This is for the least surprising, since there is no reason to stop there. 


\section{The Results}

Table 1 provides for the descriptive statistics of the 17 selected corporate stocks and the market stock index adopted. The lowest average annualized return is $7.63 \%$ and belongs to the stock market index (S\&P 500). There is one exception: the average annualized return of IBM is $6.404 \%$, however the IBM median return is $9.973 \%$. The remaining 16 corporate stocks have average annualized returns ranging between 9.223\% (American Express), and $16.920 \%$ (Walmart).

The lowest volatility, or standard deviation, of returns is for IBM with a value of $12.404 \%$. This is lower than the volatility of the returns of the stock market index. Perhaps IBM has a low beta (or systematic risk). In addition eight other corporate stocks have volatilities that are less than the volatility of the stock market index. These are: $3 \mathrm{M}$, Chevron, Coca Cola, Johnson \& Johnson, Mobil, Pepsi, Pfizer, and Procter and Gamble. This is surprising. The highest volatilities are for Boeing and Disney, for which the volatilities are close to $31.7 \%$.

There is no pattern in the comparison between mean returns and median returns. Some have the two close to each other: Mobil and Pepsi. Others have the median higher: 3M, Amex, Boeing, Caterpillar, Chevron, Disney, IBM, Johnson, Merck, and United Tech. And others have the mean higher: the market index, Coca Cola, GE, Pfizer, Procter and Gamble, and Walmart. The Jarque-Bera normality test finds all returns as non-normal except the return on Mobil.

Table 1. Monthly descriptive statistics

\begin{tabular}{lllllllll}
\hline & $\tilde{R}_{t+1}^{m}$ & $3 \mathrm{M}$ & AMEX & BOEING & CATERPILLAR & CHEVRON & COLA & DISNEY \\
\hline Average & 7.630 & 10.378 & 9.223 & 12.631 & 9.580 & 11.335 & 13.421 & 12.052 \\
Median & 3.938 & 13.636 & 14.134 & 17.218 & 12.182 & 16.430 & 12.451 & 19.018 \\
Std dev & 23.682 & 20.753 & 30.746 & 31.761 & 28.949 & 22.749 & 22.811 & 31.730 \\
Count & 667 & 572 & 667 & 667 & 667 & 572 & 667 & 667 \\
\hline
\end{tabular}

\begin{tabular}{lllllllll}
\hline & GE & IBM & JOHNSON & MOBIL & MERCK & PEPSI & PFIZER & PROCTER \\
\hline Average & 9.246 & 6.404 & 12.144 & 12.535 & 9.580 & 11.335 & 13.421 & 11.197 \\
Median & 5.045 & 9.973 & 13.003 & 12.445 & 12.480 & 11.497 & 12.742 & 0.0965 \\
Std dev & 23.712 & 12.404 & 20.329 & 17.298 & 28.949 & 22.749 & 22.811 & 19.553 \\
Count & 667 & 667 & 572 & 572 & 572 & 544 & 543 & 572 \\
\hline
\end{tabular}

\begin{tabular}{lll}
\hline & UNITED TECH & WALMART \\
\hline Average & 13.043 & 16.920 \\
Median & 16.589 & 15.178 \\
Std dev & 26.277 & 29.813 \\
Count & 572 & 542 \\
\hline
\end{tabular}

Table 2 highlights the cells, the combinations of EIS and CRRA, which are statistically insignificant. A rule of thumb is used. If there are 15 or more companies out of the 17 that conform to this yardstick, then the cell is highlighted as a possible solution. The CRRA is chosen to vary between zero and 50, and the EIS is chosen to vary between 0.1 and infinity, but mostly up to 5 . This is in accordance with the expectation that the EIS is likely to be below 3, and that the CRRA is likely to reach 50 in some special cases.

In general, a relatively large EIS, equal or higher than 1.25 and thus till infinity, is needed to be consistent with the Euler equation (1) when the CRRA is equal to or below 0.5. But it is also consistent for CRRAs of 30 and 50. Therefore there is more than one solution. An imprudent researcher may report inadvertently the much higher estimates of the CRRA. Or, even the statistical software and a different econometric procedure may pick up the 
wrong estimate. Multiple solutions indicate the possibility of multiple minima, or multiple maxima, for the solution of the optimization algorithm.

A CRRA of 0.95 in consistent with an EIS of 1.05, and a CRRA of 1.05 is consistent with an EIS of 0.95 . This is strong evidence that $\log$ utility and unitary EIS are not rejected. Nonetheless other much higher CRRAs are also consistent with an EIS of 0.95 and of 1.05. They range between a CRRA of 2.5 up to a CRRA of 50. A high EIS is therefore consistent with very high CRRAs, breaking down the intuitive inverse relation between the two. In addition, this denotes that there is not only more than one solution for the CRRA for consistency to hold, but also a steady wide range of CRRAs. Even an estimate of the EIS slightly lower than one, between 0.83 and 0.71 , is consistent with multiple solutions and wide ranges of the CRRA. Moreover an EIS of 0.71 is consistent with three ranges of the CRRA, between 1.25 and 1.5, between 2 and 3.5, and from 15 to 50. An EIS of 0.63 is consistent with similar multiple ranges, between 1.25 and 1.5, between 3 and 7, and from 20 to 50. An EIS of 0.56 has also three ranges of solutions, between 1.5 and 1.75, between 3 and 5, and from 20 to 50. For an EIS between 0.38 and 0.5 the first range of solutions is similar, between 1.5 and 2. However the second range is centered between 16 and 17, and the third range is exactly at 50. For an EIS between 0.2 and 0.33 , the first range of solutions is also similar, between 1.75 and 2.5. The second range of solutions hovers around 10 and 30, while a third range of solutions lies between 20 and 30 . An EIS between 0.1 and 0.17 has exceptionally two ranges of solution for the CRRA, instead of three, between 2 and 4 and at 50 (with a few exceptions).

Table 2. Data table for the EIS and the CRRA

\begin{tabular}{|c|c|c|c|c|c|c|c|c|c|c|c|c|c|c|c|c|c|c|c|c|c|c|}
\hline EIS $\downarrow$ & $\rho \downarrow$ & CRRA $\rightarrow 0$ & 0.5 & 0.95 & 1.05 & 1.25 & 1.5 & 1.75 & 2 & 2.5 & 3 & 3.5 & 4 & 5 & 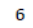 & 7 & 8 & 10 & 15 & 20 & 30 & 50 \\
\hline 0.1000 & 10.00 & 0 & 1 & 1 & 1 & 4 & 6 & 9 & 15 & 16 & 15 & 16 & 15 & 11 & 1 & 1 & 0 & 0 & 0 & 0 & c & 0 \\
\hline 0.1111 & 9.00 & 0 & 1 & 1 & 1 & 4 & 6 & 10 & 15 & 16 & 16 & 16 & 15 & 9 & 1 & 1 & 0 & 0 & 0 & 0 & c & 0 \\
\hline 0.1250 & 8.00 & 0 & 1 & 1 & 1 & 4 & 7 & 11 & 16 & 16 & 16 & 16 & 15 & 7 & 1 & 0 & 0 & 0 & 0 & 0 & & 6 \\
\hline 0.1429 & 7.00 & 0 & 0 & 1 & 1 & 4 & 7 & 11 & 16 & 15 & 16 & 15 & 14 & 2 & 1 & 0 & 0 & 0 & 0 & 0 & ( & 17 \\
\hline 0.1667 & 6.00 & 0 & 0 & 1 & 1 & 4 & 7 & 12 & 16 & 15 & 16 & 15 & 11 & 1 & 1 & 0 & 0 & 0 & 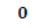 & 0 & 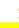 & 17 \\
\hline 0.2000 & 5.00 & 0 & 0 & 1 & 1 & 4 & 9 & 15 & 16 & 16 & 16 & 14 & 8 & 1 & 0 & 0 & 0 & 0 & 0 & 0 & 1 & 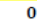 \\
\hline 0.2083 & 4.80 & 0 & 0 & 1 & 1 & 4 & 9 & 15 & 16 & 16 & 16 & 14 & 6 & 1 & 0 & 0 & 0 & 0 & 0 & 1 & 1 & 0 \\
\hline 0.2174 & 4.60 & 0 & 0 & 1 & 1 & 4 & 9 & 15 & 16 & 16 & 15 & 12 & 5 & 1 & 0 & 0 & 0 & 0 & 0 & 5 & 1 & 0 \\
\hline 0.2273 & 4.40 & 0 & 0 & 1 & 1 & 4 & 9 & 16 & 16 & 16 & 15 & 11 & 5 & 1 & 0 & 0 & 0 & 0 & 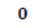 & 14 & 1 & \\
\hline 0.2381 & 4.20 & 0 & 0 & 1 & 1 & 4 & 9 & 16 & 15 & 16 & 15 & 10 & 4 & 1 & 0 & 0 & 0 & 0 & 0 & 16 & 1 & 0 \\
\hline 0.2500 & 4.00 & 0 & 0 & 1 & 1 & 4 & 10 & 16 & 15 & 16 & 15 & 9 & 3 & 1 & 0 & 0 & 0 & 0 & 2 & 17 & 17 & 0 \\
\hline 0.2632 & 3.80 & 0 & 0 & 1 & 1 & 4 & 11 & 16 & 15 & 16 & 14 & 8 & 3 & 1 & 0 & 0 & 0 & 0 & 11 & 17 & & 0 \\
\hline 0.2778 & 3.60 & 0 & 0 & 1 & 1 & 4 & 11 & 16 & 15 & 16 & 14 & 5 & 1 & 1 & 0 & 0 & 0 & 0 & 16 & 17 & ( & 0 \\
\hline 0.2941 & 3.40 & 0 & 0 & 1 & 1 & 4 & 12 & 16 & 15 & 16 & 12 & 5 & 1 & 1 & 0 & 0 & 0 & 1 & 17 & 17 & & 0 \\
\hline 0.3125 & 3.20 & 0 & 0 & 1 & 2 & 5 & 12 & 16 & 15 & 16 & 11 & 5 & 1 & 1 & 0 & 0 & 0 & 4 & 17 & 17 & & 0 \\
\hline 0.3333 & 3.00 & 0 & 0 & 1 & 3 & 6 & 13 & 15 & 16 & 15 & 9 & 3 & 1 & 1 & 0 & 1 & 2 & 16 & 17 & 3 & ( & 0 \\
\hline 0.3571 & 2.80 & 0 & 0 & 1 & 3 & 7 & 15 & 15 & 16 & 15 & 6 & J & 1 & 1 & 1 & 3 & 8 & 17 & 17 & 0 & & 1 \\
\hline 0.3846 & 2.60 & 0 & 0 & 1 & 3 & 7 & 16 & 15 & 16 & 13 & 5 & 3 & 1 & 1 & 3 & 9 & 16 & 17 & 10 & 0 & & 17 \\
\hline 0.4167 & 2.40 & 0 & 0 & 1 & 3 & 7 & 16 & 15 & 16 & 12 & 5 & 3 & 2 & 4 & 10 & 16 & 17 & 17 & 0 & 0 & ( & 17 \\
\hline 0.4545 & 2.20 & 0 & 0 & 1 & 3 & 9 & 15 & 16 & 16 & 7 & 5 & 4 & 5 & 11 & 16 & 17 & 17 & 17 & 0 & 0 & & 17 \\
\hline 0.5000 & 2.00 & 0 & 0 & 1 & 3 & 10 & 15 & 16 & 15 & 6 & 5 & 5 & 9 & 16 & 17 & 17 & 17 & 0 & 0 & 0 & 1 & 17 \\
\hline 0.5556 & 1.80 & 0 & 0 & 1 & 4 & 13 & 15 & 16 & 12 & 6 & 8 & 15 & 16 & 17 & 17 & 15 & 0 & 0 & 0 & 0 & 1 & 17 \\
\hline 0.6250 & 1.60 & 0 & 0 & 1 & 4 & 16 & 16 & 13 & 8 & 12 & 16 & 17 & 17 & 17 & 0 & 0 & 0 & 0 & 0 & 17 & 1 & 17 \\
\hline 0.7143 & 1.40 & 0 & 0 & 1 & 4 & 15 & 16 & 10 & 15 & 17 & 17 & 17 & 7 & 0 & 0 & 0 & 0 & 0 & 17 & 17 & 1 & 17 \\
\hline 0.8333 & 1.20 & 0 & 0 & 0 & 7 & 16 & 16 & 17 & 17 & 1 & 0 & 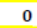 & 0 & 0 & 0 & 17 & 17 & 17 & 17 & 17 & 1 & 17 \\
\hline 0.9524 & 1.05 & 0 & 0 & 0 & 16 & 17 & 0 & 0 & 0 & 17 & 17 & 17 & 17 & 17 & 17 & 17 & 17 & 17 & 17 & 17 & 1 & 17 \\
\hline 1.0526 & 0.95 & 0 & 0 & 16 & 0 & 0 & 0 & 0 & 0 & 17 & 17 & 17 & 17 & 17 & 17 & 17 & 17 & 17 & 17 & 17 & 1 & 17 \\
\hline 1.2500 & 0.80 & 17 & 16 & 7 & 1 & 0 & 0 & 0 & 0 & 0 & . & 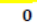 & 0 & 0 & 6 & 17 & 17 & 17 & 17 & 17 & 1 & 17 \\
\hline 1.6667 & 0.60 & 16 & 16 & 4 & 1 & 0 & 0 & 0 & 0 & 0 & 0 & 0 & 0 & 0 & 0 & 0 & 0 & 0 & 17 & 17 & 1 & 17 \\
\hline 2.5000 & 0.40 & 16 & 15 & 3 & 1 & 0 & 0 & 0 & 0 & 0 & 0 & 0 & 0 & 0 & 0 & 0 & 0 & 0 & 0 & 17 & 1 & 17 \\
\hline 5.0000 & 0.20 & 16 & 16 & 3 & 1 & 1 & 0 & 0 & 0 & 0 & 0 & 0 & 0 & 0 & 0 & 0 & 0 & 0 & 0 & 0 & 1 & 17 \\
\hline$\infty$ & 0.00 & 15 & 10 & 1 & 1 & 1 & 0 & 0 & 0 & 0 & 0 & 0 & 0 & 0 & 0 & 0 & 0 & 0 & 0 & 0 & 1 & 17 \\
\hline
\end{tabular}

\section{Conclusion}

This paper has adopted the "recursive" non-expected utility aggregator introduced by Epstein and Zin (1987, 1991, 2013). See also Weil $(1989,1990)$. The procedure involves simulation with actual data the variations in the preference function and to calculate its unconditional mean. The two parameters, which are assumed to be different, and which are the EIS and the CRRA, are varied together by forming a data table in EXCEL. Some 17 stocks are picked up for the statistical analysis from the Dow Jones Industrial Average, and the range of values that find a statistically insignificant, at the $2.5 \%$ confidence level, unconditional mean of the Euler equation are put in a repertoire and summed up for the seventeen stocks. In the final analysis the maximum frequency is therefore 17. This means that the 17 stocks have all been characterized by insignificant t-statistics for this stated combination of EIS and CRRA. I have chosen to highlight and study all frequencies above 15, including 15 . The results show that there are multiple solutions for the CRRA when the EIS is fixed. Multiple solutions can reach up to three. In addition, for each solution there is a wide range of values that satisfy the requirement of an insignificant t-statistic. The intuitive concept that the EIS and the CRRA are inversely related does not find support in this paper, as high values of the EIS 
are associated with high values for the CRRA. Lastly, the model finds that log utility is within the acceptable limits. Hence a unitary EIS and a unitary CRRA are jointly consistent with the simulations undertaken and the underlying theory.

\section{References}

Benninga, S. (2014). Financial Modeling. Cambridge, MA: MIT Press.

Breeden, D. T. (2005). An intertemporal asset pricing model with stochastic consumption and investment opportunities. Journal of Financial Economics, 7, 265-296. https://doi.org/10.1016/0304-405X(79)90016-3

Epstein, L. G., \& Zin, S. E. (1987). Substitution, risk aversion, and the temporal behavior of asset returns: II: An empirical investigation. Manuscript. University of Toronto and Queen's University.

Epstein, L. G., \& Zin, S. E. (1991). Substitution, risk aversion, and the temporal behavior of consumption and asset returns: An empirical analysis. Journal of Political Economy, 99(2), 263-286. https://doi.org/10.1086/261750

Epstein, L. G., \& Zin, S. E. (2013). Substitution, risk aversion and the temporal behavior of consumption and asset returns: A theoretical framework. Handbook of the Fundamentals of Financial Decision Making: Part I, pp. 207-239. https://doi.org/10.1142/9789814417358_0012

Hall, R. E. (1978). Stochastic implications of the life cycle-permanent income hypothesis: theory and evidence. Journal of Political Economy, 86(6), 971-987. https://doi.org/10.1086/260724

Hall, R. E. (1988). Intertemporal substitution in consumption. Journal of Political Economy, 96(2), 339-357. https://doi.org/10.1086/261539

Hansen, L. P., \& Singleton, K. J. (1982). Generalized instrumental variables estimation of nonlinear rational expectations models. Econometrica: Journal of the Econometric Society, 1269-1286. https://doi.org/10.2307/1911873

Kim, D., \& Ryou, J. (2012). Time preference and saving rate: implications for global imbalances. Journal of Money and Finance, 26(3), 61-91.

Kocherlakota, N. R. (1996). The equity premium: It's still a puzzle. Journal of Economic Literature, 34(1), 42-71.

Kreps, D. M., \& Porteus, E. L. (1978). Temporal resolution of uncertainty and dynamic choice theory. Econometrica: Journal of the Econometric Society, 185-200. https://doi.org/10.2307/1913656

Kreps, D. M., \& Porteus, E. L. (1979). Dynamic choice theory and dynamic programming. Econometrica: Journal of the Econometric Society, 91-100. https://doi.org/10.2307/1912348

Lucas, R. E. Jr. (1978). Asset prices in an exchange economy. Econometrica: Journal of the Econometric Society, 1429-1445. https://doi.org/10.2307/1913837

Mehra, R., \& Prescott, E. C. (1985). The equity premium: A puzzle. Journal of Monetary Economics, 15(2), 145-161. https://doi.org/10.1016/0304-3932(85)90061-3

Rubinstein, M. (2005). The valuation of uncertain income streams and the pricing of options. Theory of Valuation, 25-51. https://doi.org/10.1142/9789812701022_0002

Samson, L., \& Armstrong, M. (2007). Preferences and observed risk premia: an empirical analysis. Applied Economics Letters, 14(6), 435-439. https://doi.org/10.1080/13504850601057823

Stock, J. H., \& Wright, J. H. (2000). GMM with weak identification. Econometrica, 68(5), 1055-1096. https://doi.org/10.1111/1468-0262.00151

Thimme, J. (2017). Intertemporal substitution in consumption: A literature review. Journal of Economic Surveys, 31(1), 226-257. https://doi.org/10.1111/joes.12142

Weber, C. E. (2000). "Rule-of-thumb" consumption, intertemporal substitution, and risk aversion. Journal of Business \& Economic Statistics, 18(4), 497-502.

Weil, P. (1989). The equity premium puzzle and the risk-free rate puzzle. Journal of Monetary Economics, 24(3), 401-421. https://doi.org/10.1016/0304-3932(89)90028-7

Weil, P. (1990). Nonexpected utility in macroeconomics. The Quarterly Journal of Economics, 105(1), 29-42. https://doi.org/10.2307/2937817 